\title{
The Falun Gong, organ transplantation, the holocaust and ourselves
}

Tom Treasure

J R Soc Med 2007;100:119-121

The numbers of organ transplants performed in China and the speed with which organs become available has raised international concern about the source of organs. It is publicly declared that organs come from executed criminals and that consent is given. However, there are allegations of an even more macabre scenario- that prisoners are systematically subjected to surgery specifically to remove their organs for transplantation. In this essay I explore the plausibility of this claim against our knowledge of doctors' complicity with the events leading to the holocaust and the practicalities of contemporary organ transplantation.

Organ transplantation has increased in China at a remarkable rate. One institution reported 647 liver transplant operations in about a year. The waiting times are between 1-2 weeks according to Chinese hospital web pages. Price lists are available with US dollar charges well below others in a global health market and under a tenth of those in the USA. ${ }^{1}$ To become organ donors people have to die young, and under particular circumstances, which means that organs are generally scarce and waiting times can be long. In China there is a numerical gap between the likely number of donors and the number of organs evidently available, in spite of that fact that organ donation has met with resistance in Chinese culture. From May 2006 organ transplantation came under regulation for the first time; ${ }^{2}$ but the question still arises about how these transplant teams have achieved such rapid expansion and such short waiting times. An allegation has been made that in China the bodies of healthy living people have been systematically eviscerated and their organs taken for transplantation. ${ }^{3}$

It is now accepted as fact that the organs of executed criminals in China are used for transplantation. ${ }^{2}$ It is claimed that they consent, but can this be freely given? That apart, an argument of the greater good and lesser evil can be invoked: if an individual has lost the right to life under judicial process, perhaps he has also lost the right to have his kidneys buried with him. Why should they be wasted when two innocent victims of renal failure could have an improved and extended life?

Thoracic Unit, Guy's Hospital, St Thomas' Street, London SE1 9RT, UK E-mail: tom.treasure@gmail.com
However, there is a still greater concern. As part of an expansion in religious activity into the ideological vacuum left by the collapse of communism, a spiritual movement called the Falun Gong has emerged. Practitioners meet to perform their exercises and to meditate. They are pacifist by inclination and seek to meld modern science with Chinese traditions. It is hard to determine why they have attracted such disfavour, but they are cast as seditious and undesirable. ${ }^{4}$ It seems that they are incarcerated in their tens of thousands in order to correct their way of thinking. Apparently when arrested, they are routinely blood tested. There is no reason to believe that it is for the benefit of the Falun Gong - blood group matching, however, is critical to organ donation. The suspicion that Falun Gong practitioners are a source of organs is central to the investigative work of David Matas and David Kilgour who have formulated the allegation. ${ }^{3}$

The recipients are predominantly those travelling internationally for health care. If Matas and Kilgour are correct, the organs come from incarcerated members of an innocent sect-and the perpetrators are of necessity medical practitioners. As the allegation unfolds, the story seems horrific to the point of being almost beyond belief. So alarmed was I on learning of this allegation that I struggled to make sense of it. The element of the story that horrifies me most, if it is true, is that it is my medical colleagues, the doctors, who perpetrate these acts. This is the only element that I have the capacity to address. While I cannot get more evidence than has already been offered, ${ }^{3}$ I can at least test this allegation for credibility.

Transplantation of kidney, liver, cornea, heart and lung offer benefit in survival and/or life quality for the recipients, in an approximate descending order of quality adjusted life years (QALYs) gained. The sum total of QALYs donated by the dead person to others is considerable; very great indeed if multiple organs are donated and successfully transplanted into several individuals. To achieve that goal the operation on the donor and the allocation of organs must be expertly coordinated. I have been party to both removing and transplanting various organs.

My personal involvement peaked in the weekend when I successfully transplanted hearts into three patients within $72 \mathrm{~h}$. A necessary preliminary was the process of removing 
those organs and is incompatible with organ removal after execution. What happens is that an anaesthetic team continues to monitor and carefully adjust the vital physiology of the person declared brain dead, solely in order to maintain viable organs for transplantation. The heart and lungs are kept functioning while meticulous dissection and mobilization of the liver are completed. Then, in a rapid sequence, the organs - heart, lungs, liver, kidneys and then corneas - are removed, preserved and taken away. These are the necessary practicalities of the donor's operation - it should be noted that it is not compatible with retrieving organs after any process of judicial execution. The unprepared normal person might well find this both macabre and repulsive, but transplant teams necessarily become inured to these emotional and visceral responses.

How have we arrived at this point? Medical ethics are neither absolute nor static. In the West we have repeatedly challenged prior beliefs and stretched the norms of behaviour in the last few decades. For example, termination of pregnancy and manipulation of fertility (in both directions) have attracted extensive negotiation and there is still no unanimity on many points. The distinction between life and death has been redefined, specifically for the benefit of transplantation. A kidney from a cadaver can recover while the recipient is supported on dialysis, but once the myocardium necroses, the heart is irretrievably dead. It was the absence of a heartbeat that defined death until the advent of heart transplantation very publicly forced the issues in the late 1960s. Once the process of dying is completed to the point that the heart stops or fibrillates, it is likely to be damaged beyond recovery. For heart transplantation to succeed, death had to be redefined as brain death. Transplantation unquestionably pushed the boundaries of what doctors would and would not do and, in turn, society accepted the new definitions. For multiple organ donation to be achieved something that would have been horrific in another time became not only tolerable but laudable under the new rules. The blunting of our visceral responses and the redefining of ethical boundaries are steps that could lead us, if we are not careful, to the ethicists' slippery slope and must be recognized as such. But can there be any possible precedent which would make even remotely credible the allegation that doctors engage in the systematic harvesting of organs from non-consenting healthy victims?

In the 1930s the first steps on the road to the holocaust were taken - and they were taken with the complicity of doctors. ${ }^{5}$ How this came about merits attention for, if we do not recognize the facts and understand how it happened, how can we guard against it happening again? In Germany, as everywhere, there were people in long-term institutional with their carers: at one end of the spectrum there is no evidence of awareness or any capacity for sensate being. The view arose, as it inevitably does, that if their lives were to slip quietly away it would be no loss. Perhaps it would be a blessing. It would surely be a relief for their families. And then there were the saved resources of time, money and love and devotion from parents and nurses that could be released for a better purpose. Their state was captured in the German phrase lebensunwertes Leben meaning 'life unworthy of life'. ${ }^{5}$

The ethical question was whether it was permissible to take any active steps to bring about their end; in parallel, the medical question that arose was how it might be done. This in itself is important because, if the stark truth of what we are doing can be masked by the argument of secondary intent, it may be found permissible to bring about the end of life. Various methods were considered. Putting in place a policy of increasing sedation to reduce any possible distress was one. Another was starvation by systematic underfeeding or a feeding a diet designed to be deficient in some essential component. But how to implement the policy?

A team of doctors was asked to devise a questionnaire, a form, on which could be collected information about the individual's functional level. The job was done and criteria were established. These questionnaires were completed on all potential lebensunwertes Leben patients by another set of doctors. It seems likely that the carers who completed these forms were inclined to overstate the degree of disability, evidently in the belief that this would bring more care to their charges rather than less. The forms then went to three independent assessors who, in turn, were asked to take a view, against proffered criteria, as to whether this was a life worth living. The second and third assessor could see the previous opinions on the form, which had the effect of encouraging unanimity. The forms were returned to a bureau and medical transport teams were dispatched to bring those individuals identified as lebensunwertes Leben to another facility where the treatment was administered. Finally, a doctor would phrase a plausible death certificate. And so it was done. The cogs turned but none knew the purpose of the whole machine. There was a paper trail, which is why we can be sure that what I have written actually happened. ${ }^{5}$ There were let outs for those who got an inkling of what was going on and demonstrated themselves to be 'not up to the task'. They could be relieved of these duties and transferred to other work. With the onset of war, incomprehensible horror ensued but it was the policies and methods developed for the lebensunwertes Leben which provided a blueprint for what followed, and doctors were implicated throughout.

So how does this relate to transplantation? Of its nature there are also cogs turning to drive this machine. The carers 
of the potential donor see no future for their ventilatordependent charges. They inform transplant coordinators who have a laudable mission to maximize the opportunities for the many potential recipients and work towards obtaining consent from the families. An international network, established on the basis of fairness, is informed of the availability of donor organs. The designated retrieval team, usually trainee surgeons or so called 'research' or transplant fellows, go where they are sent. It is nearly always at the dead of night, when the operating theatres are free and road and air routes are clear, and it is always under extreme time pressure to maximize the quality of the organs. Meanwhile the transplant teams call recipients on waiting lists and set up urgent transplant operations, in several different hospitals - all against the clock. The time pressure, the geographical dispersion, the complexity of the matching of multiple organs, the need to respect confidentiality and the anonymity of donor and recipient, and the sheer logistics of it all, means that no member of the medical staff has an overview of the whole process. Nor would they be expected to in China. This is what makes it plausible that it could happen and that doctors themselves could be largely unaware of it, or at least sufficiently distant to turn a blind eye and a deaf ear.

Revealing the exact source of all donor organs, with a complete and transparent paper trail, would be sufficient to refute the allegations; but, interestingly, it may well be difficult to do so even in countries more open than China is at present. In the circumstances in which I was involved, there was an explicit understanding that the process only starts when it is what the donor would have wished. However, the fact is that I have never been in a position to inspect the documentation of the consent process. The hearts arrived in our operating room without a name attached and, by then, the recipient was anaesthetized and we were well on the way to removing the sick heart.

Factors that make the allegations plausible are the partitioning of the logistic elements and technical steps just as described for transplantation anywhere, and the necessity for haste. What makes it credible is the numerical gap between the reported number of transplants compared with what is possible in other countries, the short waiting times and the confidence with which operations are offered in the global health market, ${ }^{1}$ and the routine blood testing of the Falun Gong.

Competing interests TT is a transplant surgeon.

\section{REFERENCES}

1 China International Transplantation Network Assistance Center. The Cost of the Transplantation. http://archive.edoors.com/render.php? uri $=$ http $\% 3 \mathrm{~A} \% 2 \mathrm{~F} \% 2$ Fen.zoukiishoku.com $\% 2$ Flist $\% 2$ Fcost. htm $+\& \mathrm{x}=$ $16 \& y=11$ (accessed 9 October 2006)

2 Zhang Feng. New Rule to Regulate Organ Transplants. http:// www.chinadaily.com.cn/china/2006-05/05/content_582847.htm (accessed 9 October 2006)

3 Matas D, Kilgour D. Report Into Allegations of Organ Harvesting of Falun Gong Practitioners. http://www.davidkilgour.ca/ (accessed 9 October 2006)

4 Chinese Embassy. http://www.chinaembassycanada.org/eng/xwdt/ t261810.htm (accessed 9 October 2006)

5 Lifton RJ. The Nazi Doctors. New York: Basic Books, 2000 